\title{
Two new species of the plant bug genus Sejanus Distant from Japan (Heteroptera: Miridae: Phylinae: Leucophoropterini), inhabiting urbanized environments or gardens
}

\author{
Tomohide Yasunaga, Tadashi Ishikawa \& Motomi Ito
}

\begin{abstract}
Two new species of the plant bug genus Sejanus Distant, S. komabanus and $S$. vivaricolus, are described from Japan, with information on their ecology. Both species are recently confirmed within urbanized environments, including the university campus in the Tokyo metropolis, and gardens and residential quarters in Kyushu. They are considered to have been widespread originally, but their populations are now fragmented and can survive only in some restricted campuses and artificial zones where traditional vegetation is partly preserved. A checklist with known distribution and a revised key are provided for proper recognition and identification of the Japanese Sejanus species.

Tomohide Yasunaga*, Research Associate, Department of Entomology, Division of Invertebrate Zoology, American Museum of Natural History, New York, NY 10024, USA. tyasunaga@amnh.org

Tadashi Ishikawa, Department of General Systems Studies, Graduate School of Arts and Science, The University of Tokyo, 3-8-1 Komaba, Meguro, Tokyo, 153-8902 Japan. chuishikawa@gmail.com Motomi Ito, Department of General Systems Studies, Graduate School of Arts and Science, The University of Tokyo, 3-8-1 Komaba, Meguro, Tokyo, 153-8902 Japan. cmito@mail.ecc.u-tokyo.ac.jp
\end{abstract}

\section{Introduction}

The genus Sejanus Distant in the phyline plant bug tribe Leucophoropterini currently comprises 40 described species, and occurs widely within the Oriental to Australian regions, as well as in the eastern Palearctic Region, and on several Pacific islands (Menard \& Schuh 2011). The majority of species inhabit warm temperate, subtropical and tropical climate zones, and appear to be associated with evergreen broadleaf trees, particularly the inflorescences; only two species, Sejanus juglandis Yasunaga and $S$. potanini (Reuter), occur in the deciduous forests of the eastern Asia.
Five species of Sejanus have hitherto been known to occur in Japan (Yasunaga 2001a, 2001b). Recently, two unknown phyline plant bug species were collected in good numbers during our field investigations within the urbanized environment of a university campus in the Tokyo Metropolis, and in the gardens and residential quarters of the Kyushu area. After careful examination, both of these phylines were confirmed to represent undescribed species belonging unequivocally to the genus Sejanus Distant. We herein describe them as new to science, and document their host associations and unique habitat preferences. A checklist with citations to the known dis- 
tributional records and an updated key to Japanese Sejanus species are also provided to aid their identifications.

\section{Materials and methods}

Dried specimens were used in general. Specimens examined are deposited in the following institutions or collections:

AMNH: American Museum of Natural History, New York, USA

NBIC: Nagasaki Biopark (Co. Ltd.) Insect Collection, Nagasaki, Japan

TYCN: T. Yasunaga Collection, Nagasaki, Japan

UMUT: The University Museum, The University of Tokyo, Japan

Matrix code labels were attached to all type specimens, which uniquely identify each specimen, and are referred to as unique specimen identifiers (USIs). The USI codes (e.g., AMNH_PBI 000123) comprise an institution and project code (AMNH_PBI) and a unique number (000123). Generally, each USI label corresponds to a single specimen; however, some USI labels correspond to a multiple specimens of a single species mounted on the same pin. Please visit the website of the Planetary Biodiversity Inventory (PBI) Project (http://research.amnh.org/pbi/ heteropteraspeciespage), or http://www.discoverlife. org for additional information on specimens examined.

Digital images of live individuals were taken by TY with Canon EOS Kiss digital camera body + Olympus OM-System (Zuiko $38 \mathrm{~mm}$ macrolens + Auto Extension Tube + T10 Ringflash). All measurements are in millimeters $(\mathrm{mm})$. Terminology follows major works treating the genus Sejanus (Schuh 1984, Yasunaga 2001a, Menard \& Schuh 2011). Synonymic lists for known species are omitted, as comprehensive catalogs covering necessary literatures are now available (Schuh 1995, 2002-2013, Kerzhner \& Josifov 1999).

\section{Taxonomy}

\section{Genus Sejanus Distant, 1910}

\section{Diagnosis}

Recognized by the small size; fuscous (sometimes reddish) basic coloration; shiny dorsum often with two ivory spots or a white fascia at the anterior margin of the cuneus; and small-sized, simple, Jor C-shaped male endosoma with a thick-rimmed, clearly visible secondary gonopore. Detailed diagnostic characters and redescriptions are provided by Menard \& Schuh (2011) and Schuh (1984).

\section{Discussion}

Schuh's comprehensive revision (Schuh 1984) documented 25 species of Sejanus from the Indo-Pacific regions. Carvalho \& Gross (1982) also recorded 23 species (22 of which were described as new) from Australia, and considered the genus to be the most diverse in the Australian Region. However, a recent revision (Menard \& Schuh 2011) suggests that the majority of species described by Carvalho \& Gross (1982) should be placed in the Australian endemic Ausejanus Menard \& Schuh, and six species of Carvalho \& Gross and four of Schuh (1984) were designated as 'incertae sedis' and in need of proper placement in other genera. Yasunaga (2001a) described three new species and recorded two additional species from Japan. As a result, 30 species are currently regarded as "true" representatives of Sejanus.

Regarding the biology of Sejanus species, almost nothing has been reported. Because most available specimens were collected by light traps, host plant associations have fragmentarily been documented for S. breviniger Yasunaga (Euphorbiaceae), S. funereus Distant (Anacardiaceae, Verbenaceae), S. juglandis Yasunaga (Juglandaceae), S. neofunereus Schuh (Euphorbiaceae, Urticaceae), and $S$. potanini (Reuter) (Betulaceae, Salicaceae) (Menard \& Schuh 2011, Yasunaga 2001a, 2001b). The immature form was reported only for $S$. potanini from northern Japan (Yasunaga 2001b). Our recent field investigations, however, could confirm strict host association and unique habitat preferences for the two new Japanese species described below (see Biology section of each species).

Multivoltine life cycles are assumed for the members inhabiting the subtropical and tropical climate zones, whereas a few species known only in the temperate and cold temperate zones have one generation per year and hibernate in the egg stage (Yasunaga 2001b). In the Ryukyus, Japan, S. neofunereus was observed to have fed on an unidentified typhrocybine leafhopper (Auchenorrhyncha: Cicadellidae) aggregated on leaves of Pilea arborescens (Link) C.B. Rob. (Urticaceae) (Yasunaga unpublished data); this observation implies some Sejanus species may be (at least partially) predaceous.

\section{Checklist of Japanese Sejanus species, with known distribution}

S. amami Yasunaga, 2001 - Japan (Ryukyus: Amami-Oshima Is.).

S. breviniger Yasunaga, 2001 - Japan (Ryukyus: Okinawa, Ishigaki and Iriomote Isls.).

S. juglandis Yasunaga, 2001 - Japan (Hokkaido, Honshu, Shikoku), Russian Primorsky Territory. 
S. komabanus Yasunaga, Ishikawa \& Ito, sp. n. - Japan (Tokyo).

S. neofunereus Schuh, 1984 - Japan (Ryukyus), China (Hong Kong), Philippines, Taiwan.

S. potanini (Reuter, 1906) - Japan (Hokkaido, Honshu, Shikoku), Continental China (Sichuan Prov.), S. Korea, Russian Primorsky Territory.

S. vivaricolus Yasunaga \& Ishikawa, sp. n. - Japan (Shikoku, Kyushu, Yakushima Is.).

\section{Key to Japanese species}

1. Hemelytron totally shiny fuscous (Figs 1219) ........................... 2

- Base of cuneus with clear, pale or ivory spots, or confluent fascia (Figs 20-23) ......5

2. Apex of metafemur clearly yellow or yelloworange (Figs 1-3, 11-13, 16, 17) ....... 3

- Metafemur entirely darkened, or its extreme apex only slightly pale (Figs 8, 9, 14, 15, 18, 19) ......................... 4

3. Larger; total body length more than $2.8 \mathrm{~mm}\left(\sigma^{7}\right) / 2.7 \mathrm{~mm}$ (o); length from apex of clypeus to cuneal fracture greater than $2.0 \mathrm{~mm}$ (Figs 16, 17) ...........S. potanini

- Smaller: total body length up to $2.6 \mathrm{~mm}$ $\left(\sigma^{7}\right) / 2.5 \mathrm{~mm}$ (ㅇ); length from apex of clypeus to cuneal fracture less than $1.9 \mathrm{~mm}$ (Figs 12,13) ............... komabanus

4. Ventral cleft of ostiolar peritreme almost straight and deep (Figs 24, 25); warm temperate zone inhabitant from Shikoku, Kyushu and Yakushima Island ... S. vivaricolus

- Ventral cleft of ostiolar peritreme rounded and shallow (Figs 26, 27); subtropical island species currently known only from Okinawa Island ................. breviniger

5. Body larger; total body length greater than $3.0 \mathrm{~mm}$ (Fig. 23); apex of metafemur yellow (Fig. 23); temperate and cold temperate zone inhabitant associated with a Japanese walnut .................. juglandis

- Body tiny; total body length up to $2.8 \mathrm{~mm}$ (Figs 20-22); metafemur almost totally darkened (Figs 20-22); currently known only from the subtropical Ryukyu Islands, associated probably with evergreen broadleaved trees ......................6

6. Antennal segment II longer than $0.88 \mathrm{~mm}$ $\left(\sigma^{7}\right) / 0.74 \mathrm{~mm}$ (o); male antennal segment II wholly black (Fig. 20); anterior ivory mark of cuneus usually confluent (Fig. 20) ..... $\ldots \ldots \ldots \ldots \ldots \ldots$. . amami

- Antennal segment II up to $0.72 \mathrm{~mm}$; base of male antennal segment II pale; anterior ivory mark of cuneus usually divided into two spots (Fig. 21), or slightly interrupted medially (Fig. 22) ............ neofunereus

\section{Descriptions of new species}

\section{Sejanus komabanus Yasunaga, Ishikawa \& Ito, sp. n.}

Figs 1-3, 10-13, 28, 30

Type material. Holotype $\sigma^{x}$, Japan: Honshu: The University of Tokyo, Komaba Campus, Meguro$\mathrm{ku}, \quad$ Tokyo, $35^{\circ} 39^{\prime} 40.80^{\prime \prime} \mathrm{N} \quad 139^{\circ} 41^{\prime} 02.01^{\prime \prime} \mathrm{E}$, from flowers of Mallotus japonicus, 26.vi.2013, T. Ishikawa (AMNH_PBI 00379668) (AMNH). Paratypes: $110^{7} 48 \%$, same data as for the holotype (AMNH_PBI 00379669-00379705, 00379871) (AMNH, UMUT, TYCN); 5007 87\%, same data except for date, 22.vi.2013 (AMNH_PBI 0037970600379842) (AMNH, UMUT, TYCN).

\section{Diagnosis}

Recognized by the moderate size, elongate oval (male)/to more ovate (female) body, totally fuscous, shiny dorsum, clearly yellow or yellow-brown apices of all femora, long, slender hypophysis of the left paramere, C-shaped endosoma with minute spines only at apex, and noticeably 8-shaped secondary gonopore. Distinguished from the superficially most similar congener, $S$. potanini, by the smaller size (Figs 12-13 vs. 16-17), and different form of the endosoma (Fig. 30 vs. 31 ); and readily from the other new species, $S$. vivaricolus, by the generally more slender body form and yellow apices of all femora (Figs $10-11$ vs. $8-9$ ).

\section{Description}

Male: Macropterous. Body almost entirely fuscous, elongate-ovate; dorsal surface shining, with uniformly distributed, brown, semierect setae. Head shiny, vertical, minutely and sparsely punctate; vertex very narrowly carinate basally. Antenna yellowish brown, except for segments III and IV smoky brown; segment II dark brown, stout, somber yellowish brown on basal 1/4-1/3. Labium shiny chocolate brown, reaching apex of metacoxa; segments II and III usually widely yellow (brown in dried specimens). Pronotum and hemelytra shiny but weakly roughened or shagreened; scutellum shallowly and transversely rugose; pleura broadly pruinose, totally fusous; hemelytral membrane dark smoky brown. All coxae fuscous, broadly pruinose; all femora shiny dark brown, with yellow or yellow brown apices; tibiae yellow, with blackish spines; tarsi brown, each with darker tarsomere III. Abdomen shiny black. Male genitalia: Figs 28, 30. Phallotheca weakly bent 

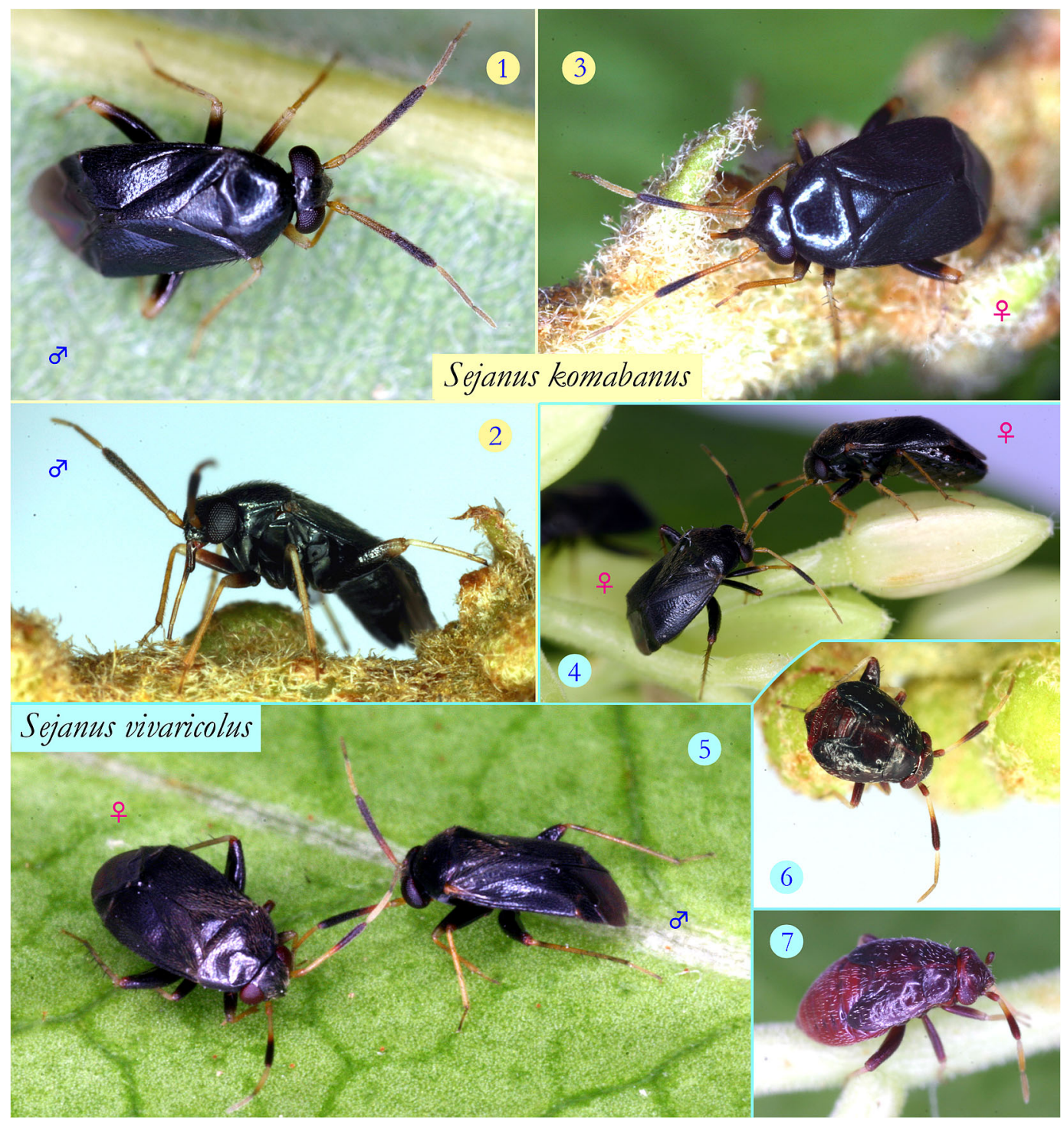

Figs 1-7. New species of Sejanus in Japan, live individuals. - 1-4, S. komabanus, adult; 4-5, S. vivaricolus, adult; 6, ditto, 4th instar nymph; 7, ditto, 5th instar nymph.

subapically, with sharpened apex. Left paramere with a slender, long hypophysis; right paramere nearly parallel-sided. Endosoma C-shaped, with apical part moderately broadened and minutely spinulate; secondary gonopore 8-shaped. Female: Macropterous. Basic coloration and structure similar to male. Body strongly ovate. Antennal segment II yellow, narrow, with infuscate, broadened apical half. Female genitalia: Sclerotized ring ovoid, with slightly projected anterolateral angle.
Measurements. $\sigma^{7} /$ : : Total body length 2.4-2.7/ 2.2-2.4; length apex of clypeus to cuneal fracture 1.78-1.89/1.69-1.81; width of head across eyes $0.69-0.74 / 0.66-0.68$; width of vertex $0.23-$ $0.27 / 0.33-0.35$; lengths of antennal segments I-IV: $0.14-0.20,0.84-0.86,0.36-0.41,0.27-0.34 / 0.15-$ $0.18,0.72-0.75,0.37-0.38,0.24-0.26$; basal pronotal width $0.86-0.94 / 0.93-1.04$; maximum width across hemelytron 1.02-1.18/1.18-1.35; width of cuneus $0.22-0.24 / 0.26-0.28$; length of cuneus 


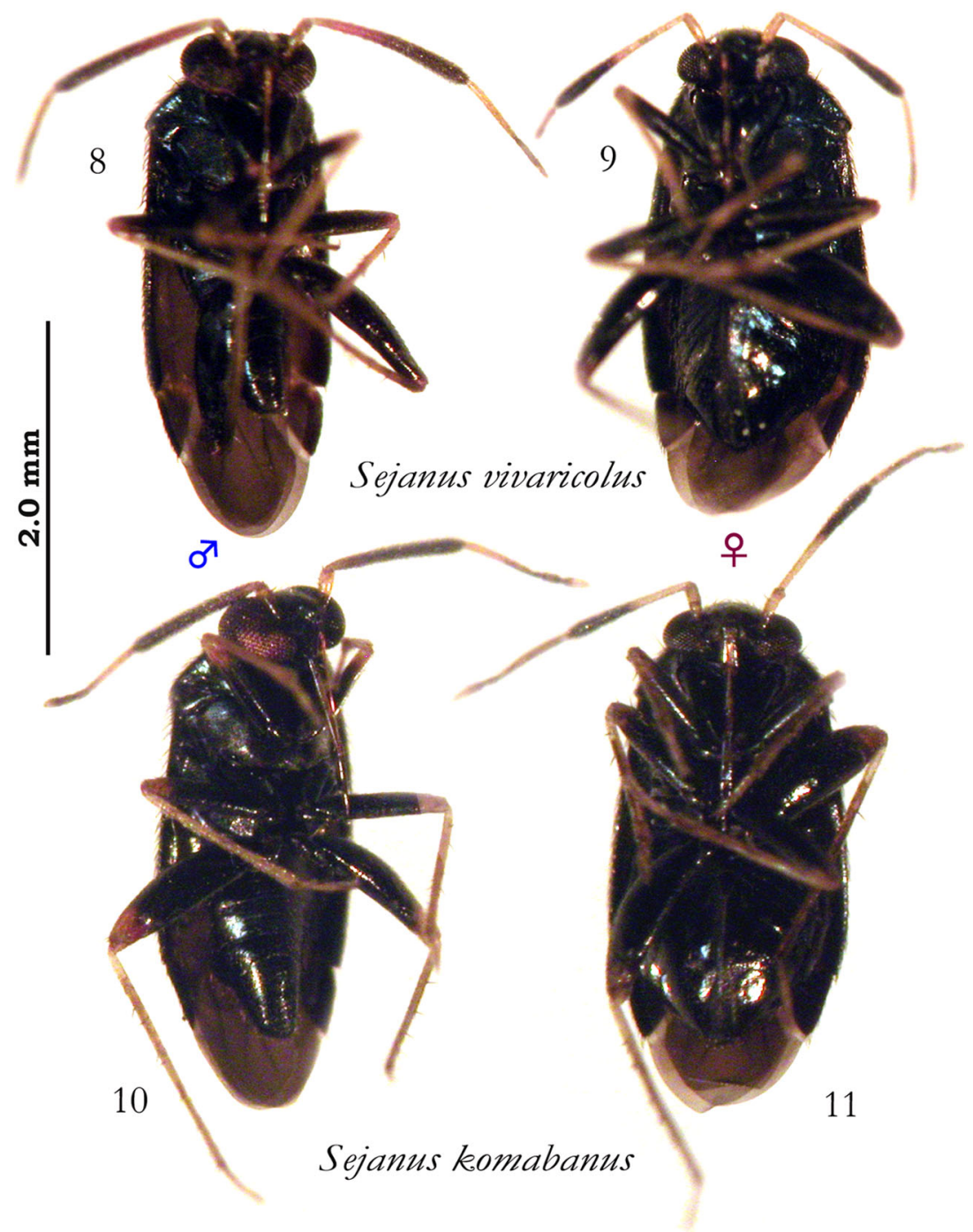

Figs 8-11. Ventral habitus images of Sejanus species. - 8-9, S. vivaricolus; 10-11, S. komabanus.

$0.39-0.44 / 0.38-0.44$; and length of metatibia $1.33-$ $1.43 / 1.23-1.38$.

\section{Etymology}

Named for the type locality, Komaba in the Tokyo Metropolis.

\section{Biology}

This new species was confirmed to be associated with Mallotus japonicus (L.f.) Müll. Arg. (Euphorbiaceae) in Tokyo, and all the adult specimens were collected in mid and late June. Consequently, a univoltine life cycle is assumed for $S$. komabanus.

\section{Sejanus vivaricolus Yasunaga \& Ishikawa,} sp. n.

Figs 4-9, 14, 15, 24, 25, 29, 34

Type material. Holotype $\sigma^{7}$, Japan: Kyushu: $\mathrm{Na}-$ gasaki Prefecture, Nagasaki Biopark [Zoo \& Botanical Garden], Saikai City, Seihi Town, Nakayama, $32^{\circ} 59^{\prime} 20^{\prime \prime} \mathrm{N} 129^{\circ} 47^{\prime} 12^{\prime \prime} \mathrm{E}$, flowers of Elaeocarpus sylvestris, 27.vii.2013, T. Yasunaga (AMNH_PBI 00379843) (AMNH). Paratypes: $150^{7} 7 \%$, same 


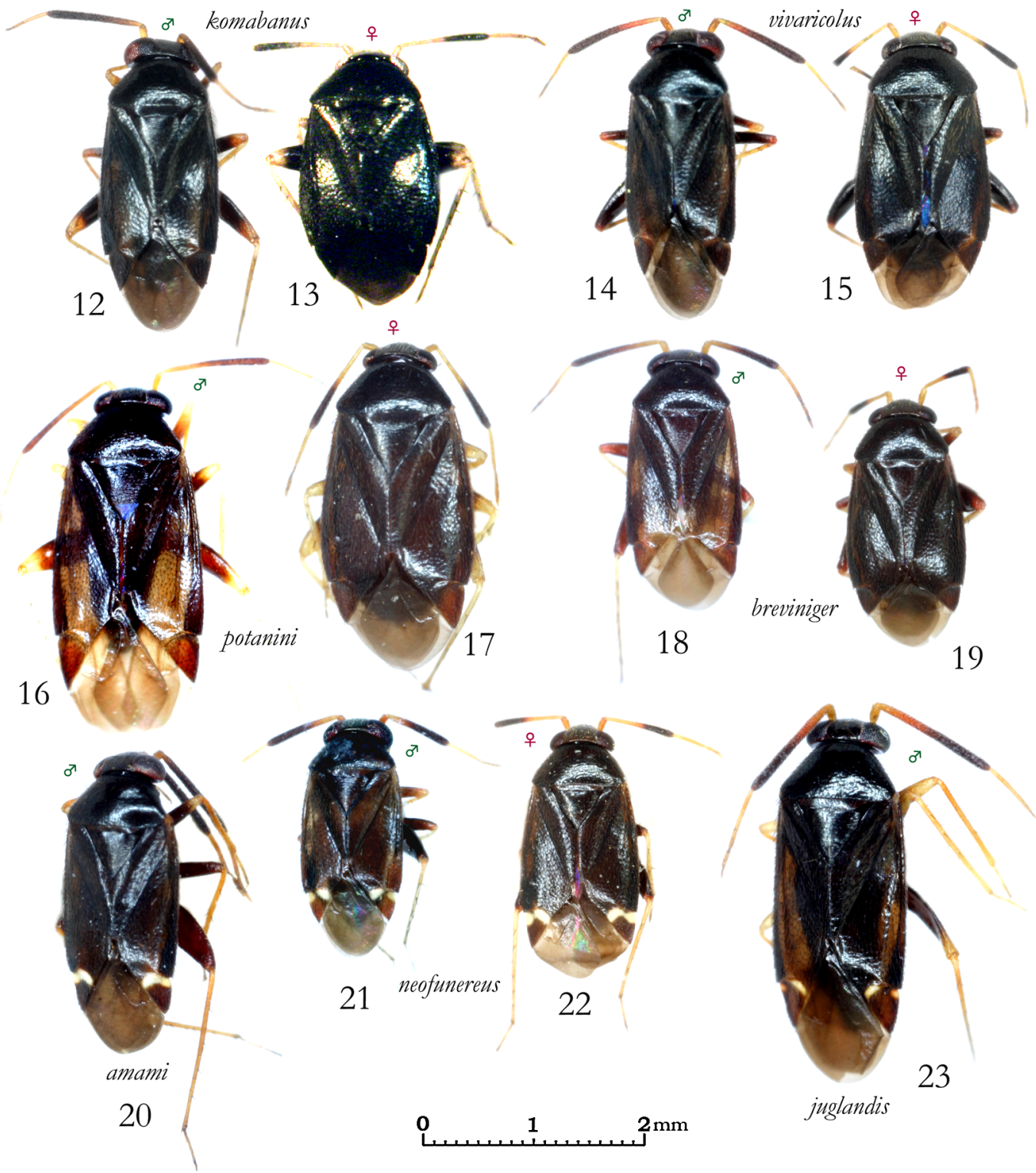

Figs 12-23. Dorsal habitus images of Sejanus species. - 12-13, S. komabanus; 14-15, S. vivaricolus; 16-17, S. potanini; 18-19, S. breviniger; 20, S. amami; 21-22, S. neofunereus; 23, S. juglandis.

data as for holotype (AMNH_PBI 0037984400379856) (AMNH, NBIC, TYCN); 407 1o, same data except for date, 2.viii.2013 (0037985700379859) (TYCN); $50^{7} 1$ 1 , same locality, 29.vi. 2013, T. Yasunaga (00379860-00379863) (TYCN); $20^{7} 2 \circ$, Nagasaki City, Nomo, Kabashima Island, $32^{\circ} 33^{\prime} 15^{\prime \prime} \mathrm{N} 129^{\circ} 46^{\prime} 30^{\prime \prime} \mathrm{E}$, flowers of Mallotus japonicus, 15.vi.2013, T. Yasunaga (0037986400379866) (TYCN); 1o, same locality, 13.vii.2013, T. Yasunaga (00379867) (TYCN); 20', Nagasaki
City, Nameshi, $32^{\circ} 48^{\prime} 39.5^{\prime \prime} \mathrm{N} 129^{\circ} 50^{\prime} 25.5^{\prime \prime} \mathrm{E}, 4$. viii.2003, flowers of Zanthoxylum ailanthoides, T. Yasunaga (00379868-00379869) (TYCN); 10", same data except for date, 29.viii.1997 (00379870) (TYCN).

\section{Diagnosis}

Recognized by the totally fuscous, weakly ovate body (Figs 4, 5, 8, 9, 14, 15), shiny dorsum, entirely dark metafemur and $\mathrm{C}$-shaped but not much curved en- 


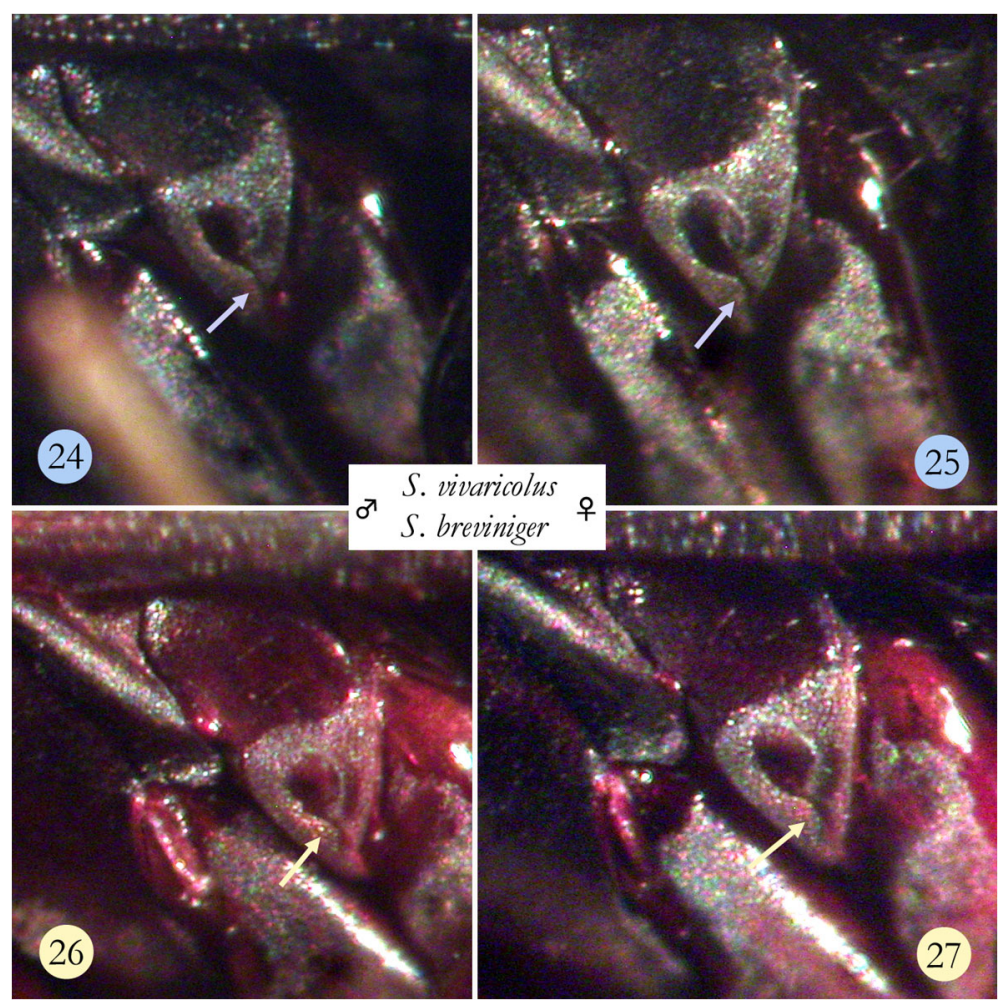

Figs 24-27. Thoracic pleurites of two closely related Sejanus species. - 24-25, S. vivaricolus; 26-27, S. breviniger.

dosoma furnished with the minute spinules on apical 1/5-1/2 (Fig. 30). Distinguished from the most closely allied congener, $S$. breviniger, by the (usually) larger size (Figs 14-15 vs. 18-19), deeper and more straight ventral cleft of the ostiolar peritreme (Figs 24-25 vs. 26-27), and different shape of the endosoma (Figs 34 vs. 32-33). The 4th (Fig. 6) and 5th (Fig. 7) instar immatures of this new species are recognized by their ovoid body shape, reddish brown basic coloration, rather shiny dorsum with uniformly distributed, silky semierect setae, darker wing pads, yellow basal halves of the antennal segment II and III, and wholly yellow tibiae.

\section{Description}

Male: Macropterous. Body totally fuscous, elongateoval, subparallel-sided; dorsal surface shining, with uniformly distributed, pale, semierect setae. Head shiny, vertical, with rather densely distributed, pale, erect setae; base of vertex slightly upturned. Antenna yellowish brown, except for segment IV brown; segment II dark brown, stout, with reddish brown basal 1/4-1/3. Labium shiny reddish brown, reaching apex of mesocoxa; segments II, III and base of IV usu- ally paler. Pronotum shiny but somewhat roughened; scutellum shallowly rugose; pleura broadly pruinose, totally fuscous. Hemelytra somewhat roughened; anterior margin of cuneus narrowly red in fresh specimens; hemelytral membrane dark smoky brown. All coxae fuscous, broadly pruinose; all femora shiny dark brown, except for apex of profemur and extreme apex of metafemur yellow or yellow-brown; tibiae yellow, with blackish spines; base of metatibia sometimes infuscate; apical part of each tarsomere III brown. Abdomen shiny black. Male genitalia: Figs 29, 34. Phallotheca roundly bent. Hypophysis of left paramere short; right paramere ovoid. Endosoma C-shaped but not much curved, with minute spinules at apical $1 / 5-1 / 2$ and a pointed projection at apex; secondary gonopore small. Female: Macropterous. Basic coloration and structure similar to male. Body oval. Antennal segment II yellow, narrow, with infuscate, broadened apical half. Female genitalia: Overall appearance very similar to $S$. komabanus, but bursa copulatrix and sclerotized rings smaller and narrower.

Measurements. $\sigma^{7} / \%$ : Total body length 2.1-2.6/ 2.2-2.5; length apex of clypeus to cuneal frac- 


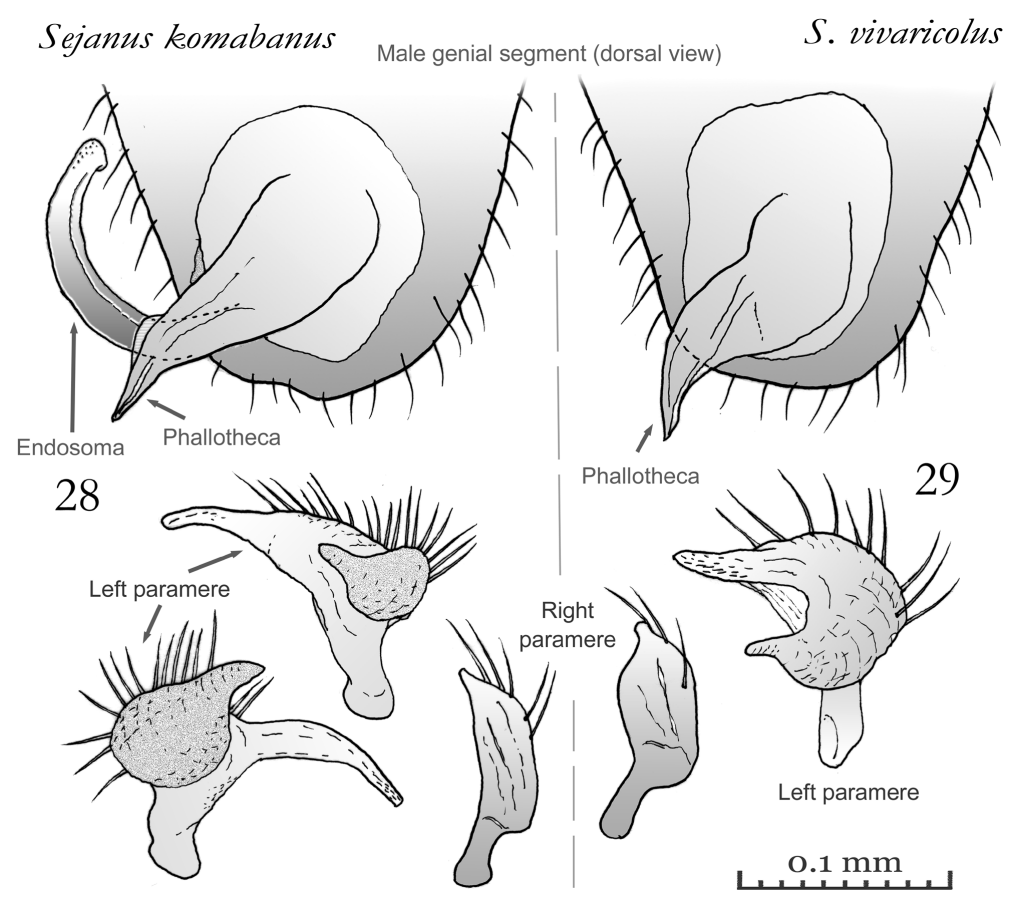

Figs 28, 29. Male genitalia of Sejanus species named on the figure. - 28, S. komabanus; 29, S. vivaricolus.

ture 1.52-1.79/1.76-1.81; width of head across eyes $0.62-0.70 / 0.67-0.68$; width of vertex $0.24-$ $0.26 / 0.28-0.30$; lengths of antennal segments I-IV: $0.14-0.18,0.72-0.88,0.33-0.36,0.24-0.27 / 0.14-$ $0.20,0.72-0.76,0.34-0.36,0.24-0.25$; basal pronotal width $0.76-0.87 / 0.93-0.96$; maximum width across hemelytron $0.85-0.96 / 1.08-1.16$; width of cuneus $0.20-0.23 / 0.22-0.24$; length of cuneus $0.31-0.38 / 0.36-0.39$; and length of metatibia 1.20 $1.44 / 1.21-1.32$.

\section{Etymology}

From Latin, vivarius (= park) in combination with suffix colus (= inhabitant), referring to the frequent occurrence of this new species in the park or garden.

\section{Biology}

This new species is associated with the broadleaf inflorescences of Mallotus japonicus (L.f.) Müll. Arg. (Euphorbiaceae) (June-July), Elaeocarpus sylvestris Poir. var. ellipticus Hara (Elaeocarpaceae) (July) and Zanthoxylum ailanthoides Siebold et Zucc. (Rutaceae) (August), in Nagasaki Prefecture, southwestern Japan. These plants are often found in and around the parks or gardens in the area. A few adults were also collected Ligustrum japonicum Thunb. (Oleaceae), but no immatures were found on this plant. A bivoltine life cycle is assumed for this mirid, and the eggs appear to hibernate.

Similar to the other new species, S. komabanus which has hitherto been discovered only in the campus of the University of Tokyo the habitats of $S$. vivaricolus appear to be restricted to the gardens (including a zoo and botanical garden) and residential quarters. This new species is yet to be discovered in montane or forest zones where the natural environments are well preserved and the abovementioned host plants also grow. Presumably, $S$. vivaricolus may prefer the border areas around mountain foothills, residential quarters and arable flatlands to deep forests, and is hypothesized to have been more widely and commonly distributed in Kyushu and Shikoku in the past. Such habitats are, however, being rapidly reduced by modern urbanization.

Additional material examined. Japan: Shikoku: $10^{7}$ 19, Kochi Pref., Cape Ashizuri, 22.v.1999, M. Takai (TYCN); $20^{7} 1$, , same data, except for date 2.vi.2000 (TYCN). Kyushu: 1\%, Fukuoka Pref., Fukuoka City, Nokonoshima Island, 21.vi.1993, T. Yasunaga (TYCN); 19, Nagasaki Pref., Azuma Town [currently Unzen City], 29.viii.1992, T. Yasunaga (TYCN); 1o, Kagoshima Pref., Yakushima Island, Ohkawanotaki, 14.vii.1994, T. Yamauchi (TYCN). 


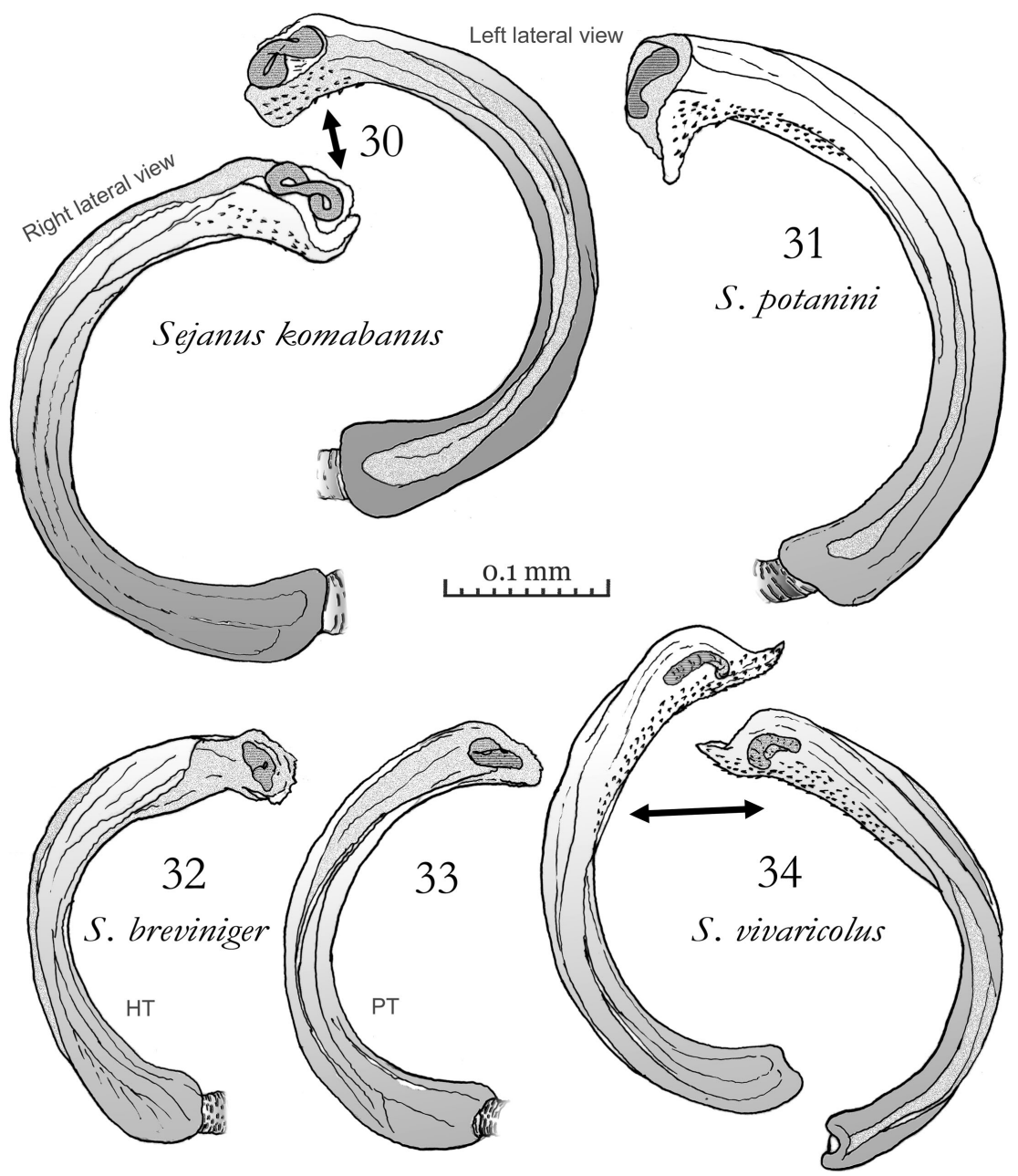

Figs 30-34. Male endosoma of Sejanus species. - 30, S. komabanus; 31, S. potanini; 32, S. breviniger, holotype (redrawn); 33, S. breviniger, paratype; 34, S. vivaricolus.

\section{Acknowledgements}

We are much indebted to the following individuals for kindly collecting or offering materials treated in this paper: Mr. M. Takai (Kochi Pref., Japan); Mr. K. Tanaka and Mr. G. Fukagawa (Nagasaki City, Japan); Mr. M. Ito and Mr. T. Ohya (Nagasaki Biopark Co. Ltd., Saikai City, Nagasaki); and Dr. K. KishimotoYamada, Mr. N. Utsuki, Dr. T. Kato, Dr. T. Iwasaki and Dr. M. Saito (the University of Tokyo). We are grateful to Dr. M. Katrina (Oklahoma, USA) and Dr. K. Yamada (Tokushima Pref., Japan) for commenting on the manuscript. Thanks are extended to Dr. T.J. Henry (Systematic Entomology Laboratory, USDA, c/o U.S. National Museum of Natural History, Washington, D.C., USA) and Dr. D. Polhemus (Department of Natural Sciences, Bishop Museum,
Honolulu, USA) for improving the manuscript with valuable comments and suggestions.

\section{References}

Carvalho, J.C.M. \& G.F. Gross, 1982. Australian antmimetic Miridae (Hemiptera: Heteroptera). I. The Leucophoroptera group of the subfamily Phylinae. Australian Journal of Zoology, suppl. ser. 86: 1-75.

Kerzhner, I.M. \& M. Josifov, 1999. Miridae Hahn, 1833. - In: B. Aukema \& C. Rieger (eds), Catalogue of the Heteroptera of the Palearctic Region, Vol. 3, Cimicomorpha II, pp. 1-576. The Netherlands Entomological Society.

Menard, K.L. \& R.T. Schuh, 2011. Revision of Leucophoropterini: Diagnoses, key to genera, description of the Australian fauna, and descriptions of new Indo- 
Pacific genera and species (Insecta: Hemiptera: Miridae). - Bulletin of the American Museum of Natural History $361: 1-159$.

Schuh, R.T., 1984. Revision of the Phylinae (Hemiptera, Miridae) of the Indo-Pacific. - Bulletin of the American Museum of Natural History 177: 1-476.

Schuh, R.T., 1995. Plant bugs of the world (Insecta: Heteroptera: Miridae). Systematic catalog, distributions, host list and bibliography. xii + 1329 pp. - The New York Entomological Society.

Schuh, R.T., 2002-2013. On-line systematic catalog of plant bugs (Insecta: Heteroptera: Miridae). - http:// research.amnh.org/pbi/catalog/
Yasunaga, T., 2001a. A review of the phyline plant bug genus Sejanus Distant in Japan (Heteroptera: Miridae: Phylinae), with descriptions of three new species. Entomological Science 4: 121-126.

Yasunaga, T., 2001b. Family Miridae Hahn, plant bugs. In: T. Yasunaga, M. Takai \& T. Kawasawa (eds), A field guide to Japanese Bugs II, pp. 112-276. Zenkoku Noson Kyoiku Kyokai Publ. Co. Ltd., Tokyo.

Received: August 19, 2013

Accepted: September 24, 2013 